九州大学学術情報リポジトリ

Kyushu University Institutional Repository

\title{
Comparison of Physicochemical Properties of Chinese and Japanese Japonica-Type Rice Varieties
}

Cui, Jing

China-Japan Joint Research Center on Palatability and Quality of Rice, Tianjin Agricultural University

\section{Zhang, Xin}

China-Japan Joint Research Center on Palatability and Quality of Rice, Tianjin Agricultural University

He, Bing

United Graduate School of Agricultural Sciences, Ehime University

Cui, Zhongqiu

United Graduate School of Agricultural Sciences, Ehime University

他

https://doi.org/10.5109/1685883

出版情報：九州大学大学院農学研究院紀要. 61 (2)，pp.281-285，2016-09-01. Faculty of Agriculture, Kyushu University

バージョン：

権利関係 : 


\title{
Comparison of Physicochemical Properties of Chinese and Japanese Japonica-Type Rice Varieties
}

\section{Jing CUI ${ }^{1}$, Xin ZHANG ${ }^{1}$, Bing HE$^{2}$ Zhongqiu CUI ${ }^{2}$, Akihito KUSUTANI ${ }^{1}$, Shoichi ITO and Yuji MATSUE*}

\author{
Department of Agricultural and Resource Economics, Faculty of Agriculture, \\ Kyushu University, Fukuoka 812-8581, Japan \\ (Received April 28, 2016 and accepted May 10, 2016)
}

\begin{abstract}
The physicochemical properties of 10 Chinese varieties were compared with those of Japanese varieties. Chinese and Japanese varieties were not significantly different in amylose content. However, maximum viscosity and breakdown value were significantly lower in the Chinese varieties than in the Japanese varieties, and protein content and hardness/adhesion ratio were higher in the Chinese varieties. In the Japanese varieties, the lower the amylose content, the lower was the protein content, which is a preferable quality for palatability. However, the lower the amylose content, the higher was the protein content in the Chinese varieties. In the Japanese varieties, the protein content was negatively correlated with amylogram properties and positively with texture properties, but the opposite tendency was observed in the Chinese varieties. Among the physicochemical properties of the Chinese varieties, the most serious problem was protein content; especially there is a need to disrupt the negative correlation between protein content and amylose content.
\end{abstract}

Key words: Chinese japonica-type rice varieties, Japanese japonica-type rice varieties, Genetic correlation, Palatability, Physicochemical properties

\section{INTRODUCTION}

Concerning the physicochemical properties of rice, the lower the amylose content, the higher was the viscosity which increases palatability (Inatsu, 1988; Matsue, 1993, 2012). Furthermore, rice with lower protein content is soft when cooked and has high viscosity which increases its palatability. In the amylogram properties of polished rice flour, the higher the maximum viscosity and breakdown value, the higher was the viscosity which results in higher palatability. Concerning the texture properties, the lower the hardness/adhesion ratio, the stronger was the viscosity of cooked rice and the higher was the palatability. Therefore, the combination of these physicochemical properties is necessary to produce highly palatable rice. Selection based on these properties is essential for breeding highly palatable rice.

Recently, the physicochemical properties of rice have also been investigated in China. However, few of these studies compared the physicochemical properties of a large number of varieties and their genetic correlation. Cui et al. (2016b) investigated and compared the physicochemical properties of 260 varieties from various districts of China. They found a negative genetic correlation between amylose and protein contents, and pointed out the importance of the disruption of the correlation in breeding palatable rice (Cui et al. 2016b). Except for this report, only a few studies have analyzed the physicochemical properties of Chinese varieties and only a few of them examined the physicochemical properties of

\footnotetext{
China-Japan Joint Research Center on Palatability and Quality of Rice, Tianjin Agricultural University

2 United Graduate School of Agricultural Sciences, Ehime University

* Corresponding author (E-mail: matsue@farm.kyushu-u.ac.jp)
}

Chinese varieties and their correlation with those of Japanese varieties (Cui et al. 1999a, 1999b, 2000; Bian et al. 2006). Therefore in this study the physicochemical properties of Chinese and Japanese varieties were compared, and the correlation between them was examined.

\section{MATERIALS AND METHODES}

\section{Used varieties and cultivation method}

In this experiment, 10 Chinese and Japanese varieties in Table 1 were used. These varieties were grown at the experimental field of Tianjin Agricultural University and Fukuoka Agricultural Research Center in 2008. Chinese varieties were cultivated at the Tianjin Stock Seed Farm at the density of 22.5 hills $\mathrm{m}^{-2}$ ( $30 \mathrm{~cm}$ row spacing and $15 \mathrm{~cm}$ hill spacing), one plant per hill. Nitrogen fertilizer was applied four times, $24.0 \mathrm{gm}^{-2}$ in total. Japanese varieties were cultivated at a density of 22.5 hills $\mathrm{m}^{-2}$ ( $30 \mathrm{~cm}$ row spacing and $15 \mathrm{~cm}$ hill spacing), one plant per hill. Amount of nitrogen application varied with the variety; it was $7.0 \mathrm{gm}^{-2}$ for Yumetsukushi and Tsukushiroman, $7.5 \mathrm{gm}^{-2}$ for Koshihikari and Mineasahi, $8.5 \mathrm{gm}^{-2}$ for Kinuhikari and Hinohikari, $9.0 \mathrm{gm}^{-2}$ for Nipponbare and Tsukushiwase, and $12.0 \mathrm{gm}^{-2}$ for Nishihomare and Tsuyaotome in total, and divided into three times.

\section{Methods of measuring physicochemical properties}

Brown rice was polished to $91 \sim 92 \%$, and it was used to investigate physicochemical properties at the ChinaJapan Joint Research Center on Palatability and Quality of Rice in Tianjin Agricultural University. Amylose and protein contents of the polished rice were measured with an auto-analyzer AA-3 (BRAN LUEBBE Co.). Protein content was shown on a dry matter basis. Amylogram 
Table 1. Outline of Chinese and Japanese varieties

\begin{tabular}{|c|c|c|c|c|}
\hline Country & No. & Variety & Feature & Region \\
\hline \multirow{10}{*}{ China } & 1 & Jinyuan45 & High yielding & \multirow{5}{*}{$\begin{array}{l}\text { Hebei } \\
\text { Province }\end{array}$} \\
\hline & 2 & Jinchuan1 & Highly palatabule & \\
\hline & 3 & No.47 & High yielding & \\
\hline & 4 & DB16 & High yielding & \\
\hline & 5 & DB14 & High yielding & \\
\hline & 6 & Jinyuan47 & Highly appearance quality & \multirow{3}{*}{$\begin{array}{l}\text { Huabei } \\
\text { Region }\end{array}$} \\
\hline & 7 & $\mathrm{bA} / \mathrm{dr} 06$ & The hybrid rice, high yielding & \\
\hline & 8 & $\mathrm{bA} / \mathrm{dr} 17$ & The hybrid rice, high yielding & \\
\hline & 9 & JinyuanD1 & High yielding & \multirow{2}{*}{$\begin{array}{l}\text { Hebei } \\
\text { Province }\end{array}$} \\
\hline & 10 & E28 & High yielding & \\
\hline \multirow{10}{*}{ Japan } & 11 & Koshihikari & Highly palatabule & \multirow{3}{*}{ Japan } \\
\hline & 12 & Kinuhikari & Highly palatabule & \\
\hline & 13 & Mineasahi & Highly palatabule & \\
\hline & 14 & Yumetsukushi & Highly palatabule & Fukuoka Prefecture \\
\hline & 15 & Nipponbare & Moderately palatabule & Japan \\
\hline & 16 & Tsukushiroman & Highly palatabule & \multirow{2}{*}{ Fukuoka Prefecture } \\
\hline & 17 & Tsukushiwase & High yielding & \\
\hline & 18 & Hinohikari & Highly palatabule & \multirow{2}{*}{ Western Japan } \\
\hline & 19 & Nishihomare & High yielding & \\
\hline & 20 & Tsuyaotome & Highly palatabule & $\begin{array}{l}\text { Fukuoka } \\
\text { Prefecture }\end{array}$ \\
\hline
\end{tabular}

properties of polished rice flour, maximum and minimum viscosities were measured by using a Rapid Visco Analyzer RVA (NEWPORAT SCIENTIFIC Co.), and breakdown value was obtained from the difference between them. The texture properties of cooked rice, hardness and adhesion were measured with Rice Hardness-Viscosity Meter RHS - 1A (SATAKE Co.) and hardness /adhesion ratio was calculated.

\section{RESULTS}

\section{Varietal difference in physicochemical properties}

Table 2 shows the physicochemical properties of the Chinese and Japanese varieties. The amylose contents of the Chinese varieties were 15.3 (No. 47) 18.4\% (Jinyuan D1), and those of the Japanese varieties were 14.8 (Tsukushiroman) 17.8\% (Nishihomare). The mean values were $17.0 \%$ and $16.2 \%$, respectively, and there was no significant difference between the mean values in the Chinese and Japanese varieties. The protein content was 8.4\% (Jinyuan D47 and E28) 11.3\% (No. 47) in the Chinese varieties, and 6.7\% (Hinohikari) 8.3\% (Nishihomare) in the Japanese varieties. The mean values were 9.2 and $7.5 \%$, respectively, and the values were significantly higher in the Chinese varieties than in the Japanese varieties.

The maximum viscosity was 120 RVU (Jinyuan D1) 227 RVU (Jinchuan 1) in the Chinese varieties, and 225 RVU (Nishihomare) 289 (Kinuhikari) in the Japanese varieties. The breakdown value was 36 RVU (Jinyuan
D1) 97 RVU (No. 47) in the Chinese varieties, and 83 RVU (Nishihomare) 124 RVU (Koshihikari) in the Japanese varieties. The hardness /adhusion ratio was 6.9 (Jinchuan 1) 35.6 (Jinyuan 47) in the Chinese varieties, and 4.3 (Tsukushiroman) 6.0 (Nishihomare) in the Japanese varieties. The mean values of maximum viscosity were 167 RVU in the Chinese varieties and 260 RVU in the Japanese varieties. The mean breakdown value was 62 RVU and 111 RVU, in the Chinese and Japanese varieties, respectively, and the mean hardness /adhesion ratio was 18.2 and 5.2, respectively. The maximum viscosity and breakdown value were significantly higher in the Japanese varieties and hardness / adhesion ratio was significantly higher in the Chinese varieties.

\section{Mutual correlation of physicochemical properties}

Fig. 1 shows the relationship between amylose and protein contents. In the Chinese varieties, a significant negative correlation was observed between them, but in the Japanese varieties, a positive but not significant correlation was observed.

Table 3 shows the mutual correlation coefficients among physicochemical properties. In both Chinese and Japanese varieties, the amylose content was negatively correlated with maximum viscosity and breakdown value, and positively with hardness/adhesion ratio. However, in the Chinese varieties, the correlation coefficient between amylose content and hardness/adhesion ratio was not significant. On the other hand, the protein content of Chinese varieties was correlated positively, though not 
Table 2. Physicochemical properties of Chinese and Japanese varieties

\begin{tabular}{|c|c|c|c|c|c|c|c|}
\hline Country & No. & Variety & $\begin{array}{c}\text { Amylose } \\
\text { content } \\
(\%)\end{array}$ & $\begin{array}{l}\text { Protein } \\
\text { content } \\
(\%)\end{array}$ & $\begin{array}{c}\text { Maximum } \\
\text { viscosity } \\
\text { (RVU) }\end{array}$ & $\begin{array}{c}\text { Breakdown } \\
\text { value } \\
\text { (RVU) }\end{array}$ & $\begin{array}{c}\text { Hardness/ } \\
\text { Adhesion ratio }\end{array}$ \\
\hline \multirow{10}{*}{ China } & 1 & Jinyuan45 & 17.6 & 8.7 & 136 & 47 & 11.6 \\
\hline & 2 & Jinchuan1 & 15.7 & 9.4 & 227 & 75 & 6.9 \\
\hline & 3 & No.47 & 15.3 & 11.3 & 223 & 97 & 23.5 \\
\hline & 4 & DB16 & 16.9 & 8.9 & 188 & 78 & 11.4 \\
\hline & 5 & DB14 & 17.1 & 10.1 & 140 & 49 & 11.7 \\
\hline & 6 & Jinyuan47 & 18.0 & 8.4 & 148 & 52 & 35.6 \\
\hline & 7 & $\mathrm{bA} / \mathrm{dr} 06$ & 17.8 & 8.6 & 152 & 54 & 15.6 \\
\hline & 8 & $\mathrm{bA} / \mathrm{dr} 17$ & 16.3 & 9.5 & 160 & 61 & 21.2 \\
\hline & 9 & JinyuanD1 & 18.4 & 8.5 & 120 & 36 & 26.8 \\
\hline & 10 & E28 & 17.2 & 8.4 & 178 & 72 & 17.8 \\
\hline \multirow{10}{*}{ Japan } & 11 & Koshihikari & 15.5 & 7.5 & 248 & 124 & 5.0 \\
\hline & 12 & Kinuhikari & 16.2 & 7.6 & 289 & 113 & 5.6 \\
\hline & 13 & Mineasahi & 16.3 & 7.7 & 247 & 106 & 5.7 \\
\hline & 14 & Yumetsukushi & 15.9 & 7.9 & 275 & 117 & 4.9 \\
\hline & 15 & Nipponbare & 16.9 & 7.3 & 250 & 108 & 5.4 \\
\hline & 16 & Tsukushiroman & 14.8 & 7.3 & 285 & 121 & 4.3 \\
\hline & 17 & Tsukushiwase & 16.0 & 6.8 & 266 & 122 & 5.4 \\
\hline & 18 & Hinohikari & 15.7 & 6.7 & 258 & 104 & 4.7 \\
\hline & 19 & Nishihomare & 17.8 & 8.3 & 225 & 83 & 6.0 \\
\hline & 20 & Tsuyaotome & 16.6 & 7.4 & 260 & 112 & 5.2 \\
\hline Mean & \multicolumn{2}{|c|}{ Chinese varieties } & $17.0 \mathrm{a}$ & $9.2 \mathrm{a}$ & $167 \mathrm{~b}$ & $62 b$ & $18.2 \mathrm{a}$ \\
\hline value & \multicolumn{2}{|c|}{ Japanese varieties } & $16.2 \mathrm{a}$ & $7.5 b$ & $260 \mathrm{a}$ & $111 \mathrm{a}$ & $5.2 \mathrm{~b}$ \\
\hline
\end{tabular}

The different small alphabets are significantly different at 5\% level.
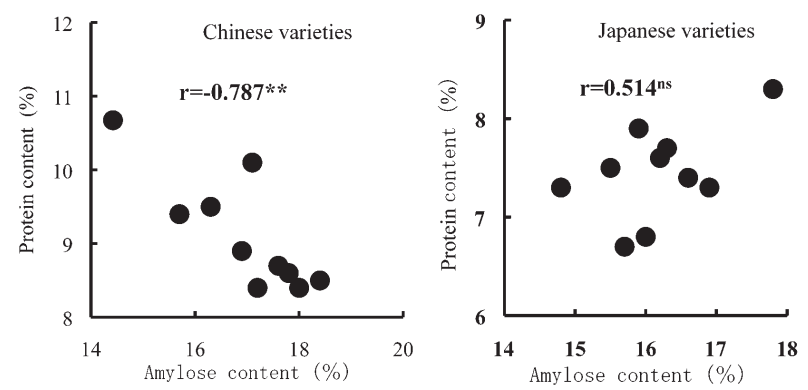

Fig. 1. Correlation between amylose content and protein content. **: Significant at $1 \%$ level. ns: Not Significant.

significantly, with maximum viscosity and breakdown value, and negatively with hardness/adhesion ratio. By contrast, in the Japanese varieties, the protein content was correlated negatively with maximum viscosity and breakdown value, but positively with hardness/adhesion ratio. In both Chinese and Japanese varieties, there was a strong positive correlation between maximum viscosity and breakdown value.

\section{DISCUSSION}

The lower the amylose content and protein content, the higher was the palatability of rice (Inatsu, 1988; Matsue, 1993, 2012). The standard value for palatable rice in Japan is an amylose content of less the 20.0\%, and protein content of less than 8.5\% (Matsue 1993). Furthermore, the higher the maximum viscosity and the breakdown value, the higher was the palatability of rice. The standard value for palatable rice is a maximum viscosity higher than 300 RVU and breakdown value larger than 100. There is no standard for hardness/adhesion ratio, but Cui et al. (2016b) reported the standard to be a hardness/adhesion ratio of less than 20 .

The mean value of amylose content was higher in the Chinese varieties than in the Japanese varieties though not significantly (Table 2). And there were no Japanese or Chinese varieties with amylose content higher than $20 \%$. The highest and the lowest protein contents were 11.3 and $8.4 \%$, respectively, in the Chinese varieties and $8.3 \%$ and $6.7 \%$, respectively, in the Japanese varieties. Thus the lowest value in the Chinese varieties was much the same as the highest value in the Japanese varieties. Therefore, the mean value was significantly higher in the Chinese varieties than in the Japanese varieties. Only one 
Table 3. Correlation coefficient among physicochemical properties

\begin{tabular}{clcccc}
\hline Country & Physicochemical property & PC & MV & BD & H/-H \\
\hline \multirow{5}{*}{ China } & Amylose content (AC) & $-0.787^{* * *}$ & $-0.874^{* *}$ & $-0.841^{* *}$ & 0.343 \\
& Protein content (PC) & & 0.529 & 0.588 & -0.121 \\
& Maximum viscosity (MV) & & & $0.932^{* * *}$ & -0.305 \\
& Breakdown value(BD) & & & -0.190 \\
& Hardness/adhesion ratio (H/-H) & & & \\
\hline \multirow{5}{*}{ Japan } & Amylose content (AC) & 0.514 & $-0.670^{*}$ & $-0.797^{* *}$ & $0.849^{* *}$ \\
& Protein content (PC) & & -0.327 & -0.474 & 0.492 \\
& Maximum viscosity (MV) & & & $0.668^{*}$ & -0.536 \\
& Breakdown value(BD) & & & -0.591 \\
& Hardness/adhesion ratio (H/-H) & & & \\
\hline
\end{tabular}

$*, * *, * * *$ : Significant at 5\%, $1 \%$ and $0.1 \%$ level, respectively.

of the Chinese varieties met the standard value of protein content, but all of the Japanese varieties met the standard.

None of the Chinese and Japanese varieties had maximum viscosity meeting the standard of 300 RVU, but the maximum viscosity was higher than $200 \mathrm{RVU}$ in all Japanese varieties. In the Chinese varieties, the maximum viscosity was higher than 200 RVU only in Junchuan 1 and No. 47. Thus, the maximum viscosity in the Chinese varieties was significantly lower than that in the Japanese varieties on the average. The breakdown value was lower than the standard value in all Chinese varieties, but in 9 of the Japanese varieties excluding Nishihomare. In the Chinese variety Jinyuan D1, the breakdown value was as low as 36 RVU. Therefore, the mean value of breakdown was significantly lower in the Chinese varieties. The hardness/adhesion ratio was lower than 10 in the Chinese varieties, although it was 7 in Jinchuan 1 . In all Japanese varieties, it was lower than 10 with a maximum of 6 in Nishihomare. The lowest hardness/adhesion ratio in the Chinese varieties was similar to the highest hardness/adhesion ratio in the Japanese varieties, which was the same tendency as in protein content. The mean value of the hardness/adhesion ratio was significantly higher in the Chinese varieties. Thus, the Chinese varieties used in this study had an amylose content similar to that in the Japanese varieties, but had lower maximum viscosity and breakdown value than the Japanese varieties, and the Chinese varieties had a higher protein content and hardness/adhesion ratio than the Japanese varieties.

Among the Chinese varieties, Jinchuan 1 had the most preferable physicochemical properties though the protein content was slightly higher. No. 47 had the lowest amylose content and superior amylogram properties, but had an extremely high protein content and high hardness/adhesion ratio. Jinchuan D1 had a low protein content, but as a whole the worst physicochemical properties. Among the Japanese varieties, Tsukushihomare and Yumetsukushi had superior physicochemical properties and Nishihomare had the worst. However, the physico- chemical properties of Nishihomare were as a whole similar to or slightly higher than the average of the Chinese varieties.

There was a significantly negative correlation between amylose and protein contents in the Chinese varieties, but not significant, a positive correlation in the Japanese varieties (Fig. 1). In the Chinese varieties, the varieties with a low amylose content had a high maximum viscosity and breakdown value and low hardness/adhesion ratio which tended to be preferable for palatability (Table 3). However, in the Chinese varieties, the varieties with a low protein content had a low maximum viscosity and breakdown value and high hardness/adhesion ratio which are not preferable for palatability (Cui et al., 2016b). Thus, the problem in physicochemical properties of Chinese varieties is protein content, and disruption of genetic negative correlation between protein content and amylose content is the most important subject in the Chinese varieties as Cui et al. (2016b) pointed out.

As mentioned above, the Chinese varieties had markedly lower physicochemical properties than the Japanese varieties. However, as described above, the Chinese and Japanese varieties were cultivated under different cultivation conditions. Especially, the amount of nitrogen application which affects the nitrogen content of grains was 2-3 times larger in the Chinese varieties than in the Japanese varieties. To obtain correct information of physicochemical properties, it is necessary to compare the Chinese and Japanese varieties under the same condition. Cui et al. (1999a 1999b, 2000, 2001) reported that the Chinese varieties had lower palatability than the Japanese varieties under the same cultivation condition. Furthermore, Bian et al. (2006) compared the physicochemical properties of Chinese varieties with those of Japanese varieties raised in different years, and reported that the palatability of Chinese varieties was similar to that of Japanese varieties bred in the 1970s. However, many Chinese varieties have superior individual physicochemical properties and by crossing these varieties, it should be possible to breed high palatable varieties in the near future. 


\section{REFERENCES}

Bian, J., H. Tada, J. Liu, F. Shiotsu, M. Morokuma, M. Toyota and A. Kusutani 2006. Comparison of yield and palatability between Chinese and Japanese rice cultivers. Shikoku J. Crop Sci. 43: $13-22^{*}$

Cui, J., A. Yamamura, A. Kusutani, M. Toyota, M. Morokuma, K. Asanuma, M. Ichii, H. Tanno, R. Zhang and D. Hong 1999a. Studies on palatability of Chinese and Japanese rice cultivarscomparison under the same cultivation condition-. Shikoku J. Crop Sci. 36: 1-13*

Cui, J., A. Yamamura, A. Kusutani, M. Toyota, M. Morokuma, K. Asanuma, H. Tanno, J. Zhao, Y. Li and X. Chen 1999b. Studies on palatability of Chinese and Japanese rice cultivarsdifference between producing districts, Kagawa in Japan and Tianjin in China-. Shikoku J. Crop Sci. 36: 14-27*

Cui, J., J. Zhao, A. Kusutani, M. Morokuma, M. Toyota, K. Asanuma and H. Tanno 2000. Studies on palatability of rice grown in Tianjin District, China-varietal difference-. Jpn. J. Crop Sci. 69: $314-319 * *$

Cui, J., A. Kusutani, J. Zhao, J. Liu, X. Chen, M. Morokuma, M. Toyota and K. Asanuma 2001. Studies on palatability of Chinese and
Japanese rice cultivars-characteristics with reference to grainprotein content-. Shikoku J. Crop Sci. 38: 1-15*

Cui, J., X. Zhang, Z. Cui, A. Kusutani, S. Ito and Y. Matsue 2016a. Correlation between evaluation of palatability by sensory test and physicochemical properties in Chinese Japonica-type rice. Fac. Agr., Kyushu Univ., 61: 53-58

Cui, J., X. Zhang, Z. Cui, X. Huang, A. Kusutani, S. Ito and Y. Matsue 2016b. Physicochemical properties related to palatability of Chines japonica-type rice. J. Fac. Agr., Kyushu Univ., 61: $59-63$

Inatsu, O. 1988. Studies on improving the eating quality of Hokkaido rice. Report of Hokkaido prefectural Agricultural Experiment Stations 66: $1-89 *$

Matsue, Y. 1993. The Effects of environmental conditions on palatability and physicochemical properties of rice and the evaluation of good eating quality rice varieties. Rep. of Special Bull. of Fukuoka Agric. Res. Cent. 6: 1-73**

Matsue, Y. 2012. Palatability Science of Rice. Yokendo, Tokyo, Japan: $1-141^{*}$

*: In Japanese.

**: In Japanese with English abstract. 